\title{
O PROCESO DE NORMATIVIZACIÓN DA LINGUA GALEGA
}

A historia da lingua galega ven determinada en tódolos seus aspectos polos seguintes factores:

- o seu pasado común co portugués

- o seu tratamento como dialecto, ben do portugués, ben do castelán

- os factores sociopolíticos e de política lingüística derivados da súa integración no Estado Español

- a situación diglósica

- a falta dunha norma escrita aceptada por todos e o suficientemente difundida

É evidente que estes elementos se interrelacionan entre si e conforman un cadro xeral bastante problemático, polo menos se o comparamos coa situación da maioría das linguas do seu entorno xeográfico. Sen dúbida houbo avances de xigante no que atinxe ó estatus político, social e literario do galego, pero existen aínda aspectos que o sitúan nun nivel de desenvolvemento e madurez inferior ó doutras linguas. Isto pode explicar, por exemplo, o escaso coñecemento que hai da súa mera existencia en Europa, mesmo no ámbito de estudios de lingüística e filoloxía, que moitas veces non o recollen nin tan sequera nos mapas das linguas europeas, dos que nunca faltan nin o catalán nin o basco. Tamén é certo que non toda a culpa é dos lingüístas de fóra; tamén desde dentro, algúns non ven con malos ollos que o galego apareza recollido como variante do portugués.

A escrita, tanto a producción como a norma, é un dos aspectos máis problemáticos pero tamén no que máis se progresou. $\mathrm{E}$, de non estar tan contaminada por factores de tipo ideolóxico, seguramente se acadarían máis metas e se solucionarían conflictos que resultan alleos á maior parte das linguas.

Previamente é preciso presentar e aclarar dous conceptos: o de normalización e o de normativización. Santamarina (en Monteagudo 1995: 125) explica a diferencia entre ámbolos dous conceptos ó defini-lo primeiro como "extensión social da lingua" e o segundo como a "escolla e formulación da norma", ou, o que é o mesmo, entendemos como normalización o proceso conducente ó emprego dunha lingua en tódolos ámbitos da vida e actividades dun pobo. Normativización é a elaboración dun modelo de regras gramaticais e ortográficas e dun corpus léxico estable recollido en gramáticas e diccionarios respectivamente, que serve de referencia ós falantes dunha lingua especialmente no momento en que a desexan plasmar por escrito. Aínda que podemos dicir que o estado dun e doutro proceso é independente, pois pódese pensar en linguas que teñan unha norma estable e non teñan un uso normalizado, e, se ben máis difícil, viceversa, a precariedade do proceso de normalización da lingua galega ten o seu reflexo na inestabilidade e o coñecemento insuficiente da norma oficial. Veremos que esta situación ten a súa explicación ou parte da súa explicación na loita de enfoques lingüísticos determinados por posturas ideolóxicas varias. 
A existencia dunha producción literaria en lingua galega medieval non se coñeceu ata o século XIX. Ata ese momento, a xente que comenzou a escribir en galego fíxoo desde unha postura bastante difícil e con certa idea de inferioridade. Os escritores do chamado Rexurdimento querían, desde unha postura reivindicativa, facer fronte ó xigante lingüístico do castelán, que tiña como unha das mostras do seu "poder" a riquísima tradición literaria, da que o galego, por aquel entón e por descoñecemento, carecía. Era pois o labor destes primeiros escritores en lingua galega dobre: por unha banda, a elaboración dun código escrito para a lingua e, pola outra, a creación dunha tradición literaria que outorgase á lingua un estatus máis elevado, o de lingua de producción literaria. É coñecido que a reivindicación en favor dos dereitos dos galegofalantes xa comenzara na época da Ilustración nas figuras de X. Cornide e Saavedra e dos padres Sobreira, Feixoo ou Martiño Sarmiento. Este último xa recoñecera os problemas que planteaba a ortografía á hora de recoller por escrito unha serie de coplas galegas. Pero non será ata a época do Rexurdimento que se manifesten con moita claridade unha serie de obstáculos e problemas principalmente no campo do léxico e a ortografía que serán constantes ó longo da historia ata os nosos días, e, por ser máis precisos, ata a reforma ortográfica da que estamos a falar. Disto falaremos con detalle máis adiante.

Temos que ser conscientes de que a lingua galega, carente de producción escrita e emprego nos ámbitos oficiais desde finais da Idade Media, reducida a unha especie de fala bárbara e inculta, se atopaba no século XIX nun estado de gran fragmentación dialectal. Se pensamos en fenómenos dialectais en linguas que teñen un carácter oficial e tradición escrita que funciona como factor de unidade, poderemos facernos unha idea de cal era a situación en Galicia despois dos Séculos Escuros. Por iso, os escritores do Rexurdimento botaron man nun primeiro momento do galego que eles coñecían, que non era outro que o galego que se falaba no seu ámbito xeográfico, moi contaminado por elementos do castelán e tamén por distorsións vulgarizantes. A división habitual que tódolos autores mencionan remóntase a Carballo Calero, que deu a esta etapa o nome de dialectalismo. A representante máis coñecida é, por suposto, Rosalía de Castro. O seguinte paso foi o interdialectalismo, durante o cal os autores entran en contacto entre sí e asumen na súa producción algunha das formas dos dialectos empregados polos outros autores. A última época desta división sería o supradialectalismo, que supón o avance cara a unha norma por encima das diferentes variedades dialectais e aceptada por todos.

Fernández Salgado e Monteagudo (Monteagudo, 1995: 134), sen embargo, consideran que esta división tradicional non se axusta á realidade ó presentar un proceso de etapas sucesivas claramente diferenciadas e sen volta atrás. Na súa opinión atópanse rasgos de dialectalismo en épocas posteriores ós intentos de tipo inter- e supradialectal. Eles, pola súa banda, propoñen a seguinte división, que remite ás teorías de Kloss e Muljačić:

- Galego popularizante (ata fins do século XIX, caracterizado polo interdialectalismo, vulgarismo, castelanismo)

- Galego enxebrizante (ata 1936, caracterizado pola selección vocabular -portugués, galego antigo, outras linguas-, hiperenxebrismos, castelanismos disfrazados, neoloxismos, ampliacións semánticas)

- Galego protoestándar (ata os 70) 
- Galego estándar (ata a actualidade, marcado polo enfrontamento dos reintegracionistas e isolacionistas).

Tanto unha coma outra división deben ser tidas en conta á hora de facer un repaso da evolución do galego escrito e a elaboración dunha norma.

Os primeiros escritores "reais" en lingua galega despois dos séculos escuros aparecen agrupados, pois, no movemento que se deu en chamar "Rexurdimento", e que se enmarca na revolución que supuxo o Romanticismo na emancipación dos pobos, a idea de liberdade e de recuperación das linguas e tradicions propias de cada rexión. Tres son os grandes nomes do Rexurdimento: Rosalía de Castro, Curros Enríquez e Eduardo Pondal. Rosalía de Castro publica en 1863 Cantares Galegos. Na súa obra acode, como xa dixemos, ó dialecto da zona de Santiago e, máis tarde, adopta elementos doutros dialectos do galego, ó entrar en contacto con outros escritores. A poesía é desde o primeiro momento o xénero literario hexemónico, pero pronto tamén se cultiva teatro e narrativa en galego. Por un lado temos os escritores que aceptan as formas procedentes do castelán, como Rosalía de Castro, mentres que outros, como Pintos, rexeitan as formas coincidentes co castelán, mesmo as etimolóxicamente lexítimas do galego, e cultivan unha vía diferencialista que se caracteriza polos hipergaleguismos e neoloxismos segundo formas de xeralización e transferencia dalguns resultados fonéticos e morfolóxicos dunhas palabras a palabras que nunca evolucionaron dese xeito (por exemplo: *zoa no lugar de zona por analoxía con persoa - persona).

Á parte da producción literaria, que funciona como primeiro intento de fixación por escrito da lingua e, por tanto, de xeito máis ou menos consciente, dunha norma, e que dá ó galego o estatus de lingua literaria, van aparecendo obras de tipo lingüístico, ben descriptivo, ben normativo sobre a lingua galega. Alguns exemplos son: Compendio de gramática gallego-castellana (1864) de Francisco Mirás, Diccionario gallego-castellano (1865) de Francisco Xabier Rodríguez, Gramática Gallega (1868) de Xoán Antonio Saco e Arce, El habla gallega. Observaciones y datos sobre su origen y vicisitudes (1868) e Diccionario Gallego (1868) de Xoán Cuveiro Piñol, Diccionario gallego-castellano (1884) de Marcial Valladares, Elementos de gramática gallega (1882) de Marcial Valladares.

Tanto os escritores como os gramáticos enfróntanse a unha serie de problemas derivados da falta de tradición e de se teren educado nun sistema castelanfalante. De aí que sexa a gramática do castelán a que serve de primeira referencia para a maioría, por non decir todos, deles. Os principais problemas son:

- acentuación

- uso ou non de apóstrofos para marcar elisión: a muller qu'está aló...

- uso ou non de guións para marcar elisión, rotacismo e lateralización: Tra-los montes (>tras os montes)

- representación gráfica da apertura das vocais (oso / óso)

- representación de fonemas como $/ \mathrm{f} / \mathrm{ou} / \mathrm{n} /$

- emprego do v/b (avogado, fronte o castelán abogado) e do h (harmonía)

- representación ou non do fenómeno da gheada e o seseo

- polimorfismo (concurrencia de dúas ou máis formas para unha mesma palabra, 
incluso no mesmo escritor ou, o que é máis curioso, na mesma obra) contraccións, esp. do artigo indefinido coa preposición $a$

No percorrido ata os nosos días irei comentando a postura respecto a algún destes aspectos.

González Seoane (1994) fala da existencia de dúas correntes no Rexurdimento, a popularista e a cultista. Os da primeira corrente, representada por Saco e Arce, avogaban por unha gramática foneticista que reflectise a lingua máis popular e rústica, que se vía como garante da pureza da lingua fronte a contaminación castelá dos falantes cultos. Os partidarios da segunda corrente, como Valladares, abominan dos vulgarismos da fala máis rústica e teñen unha vocación máis prescriptiva.

É durante este tempo cando se descobren as cantigas medievais en galego-portugués, que aportan un referente máis no proceso de elaboración dunha norma. Pero parecía evidente que xa non podía ofrecer solucións para moitos fenómenos xurdidos tras uns sete séculos de evolución e de influencia do castelán.

En 1905 fúndase a Real Academia Galega baixo a dirección de Manuel Murguía, coa función de elaborar unha gramática e un diccionario. Neste marco é no que xorden as discusions en torno a aspectos concretos como a representación da contracción de preposición a co artigo indefinido. Así temos aoístas (que propoñen a forma lusa $a o$ ) e oístas (máis foneticistas, que propoñen a forma ó). Outro punto de discordia e a representación do fonema $/ \mathrm{J} /$. Os etimoloxistas optan pola representación mediante as grafías $\mathrm{j}$, g e x, moi próximo ó xeito portugués, dacordo co étimo latino correspondente, así: juvenil $(>$ lat. iuvenis), gente ( $>$ lat. gens) e dixen ( $>$ lat. dixi). Mentres que os non etimoloxistas, que coinciden prácticamente coa corrente foneticista, propoñen o emprego de $\mathrm{x}$ en tódolos casos nos que se teña que representa-lo fonema $/ \mathrm{J} /$.

Nos primeiros anos do século XX aparecen, sempre neste contexto dunha maior concienciación e proceso reivindicativo do galego, as Irmandades da Fala. Fíxanse como meta a defensa de Galicia e do seu idioma propio. Ás Irmandades pertencen personalidades tan importantes como Cabanillas e Vilar Ponte. Dentro deste grupo atópanse os que están máis centrados na loita política a carón dos que dan máis importancia ó labor cultural. Son estes os que asumen moitas das tarefas que, de por sí, lle corresponderían á Real Academia Galega: a elaboración de gramáticas e diccionarios. Son froito obras como Compendio de gramática galega (1919) de Leandro Carré Alvarellos ou Gramática do Idioma Galego (1922) de Manuel Lugrís Freire. Pero un dos méritos máis importantes das Irmandades é a edición da revista $A$ Nosa Terra, que se converte nun referente indiscutible para tódolos intelectuais embarcados na normalización e normativización do galego. Este órgano asumirá, por exemplo, as normas recollidas en Algunhas normas para a unificación do idioma galego (1933), do Seminario de Estudios Galegos - fundado pola súa banda en 1923.

O Seminario supón un paso adiante na dignificación do galego, xa lingua de producción literaria e agora tamén de ciencia coa publicación de obras de tipo divulgativo en diversos campos. Paralelo ó Seminario actúa a Xeración Nós, que aparece englobada no movemento nacionalista. A Xeración Nós marca unha verdadeira época de ouro nas letras galegas con figuras como Risco ou Castelao, quen tamén exercerá unha importan- 
te actividade política no seo do Partido Galeguista. Unha das reivindicacións do nacionalismo é a cooficialidade do galego co castelán.

Todo isto obriga a buscar non só o acordo máis amplio posible en cuestións ortográficas, senón tamén no campo léxico para cubri-las necesidades dos novos ámbitos de uso, con vocabulario máis abstracto e científico. O castelán deixa de se-la fonte máis importante para supli-las carencias do galego e agora o portugués adquire unha inusitada importancia, e, en menor medida, o galego medieval e outras linguas europeas como o francés ou o italiano. Non é casualidade que sexa nesta época o punto no que podemos situa-lo nacemento do movemento reintegracionista. Johan Vicente Viqueira escrebe o artigo "Pol-a reforma da ortografía" (1918) con propostas que aproximarían o galego ó portugués na escrita.

Desde o Rexurdimento ata o punto de inflexión e retroceso que é a Guerra Civil e os inicios da Dictadura de Franco, podemos dicir que a normativa do galego acada unha estabilidade e aceptación considerable gracias á producción literaria e o traballo das Irmandades, o Seminario e a xente de "Nós", vinculados en maior ou menor xeito á revista $A$ Nosa Terra, que fai de propagador das formas máis empregadas e, por dicilo dalgunha forma, de referente de norma non oficial. Neste proceso podemos diferenciar dúas grandes correntes de proposta de normas: a máis foneticista e próxima á fala, e a máis etimolóxica e tendente á converxencia co portugués na escrita.

Coa Dictadura e o exilio de moitos intelectuais, Buenos Aires convértese no novo centro do galeguismo, tanto político como cultural. Sen embargo, non debemos pensar que na Península se deteñen por completo os esforzos por normaliza-lo galego. Se ben é verdade que nun comenzo só se logran publica-las obras de tintes folclóricos como os poemas de Rosalía, xa en 1950 fúndase a Editorial Galaxia e isto marca o inicio dunha actividade non só de publicación senón tamén de creación que, sen estridencias, vai gañando en importancia e calidade nos seguintes anos da Dictadura. Na década dos setenta o galego entra no ámbito universitario (creación da Cátedra de Lingua e Literatura Galega en 1972). En 1971 nace unha das institucións máis importantes da actualidade, o Instituto da Lingua Galega. Un ano antes a Real Academia Galega publicara as Normas ortográficas do idioma galego. Así pois vemos unha actividade que, aínda que tímida, será primordial no proceso de normalización que se inicia coa chegada da democracia en 1975-1977.

Coa Constitución e o Estatuto de Autonomía, o galego acada o estatus de lingua oficial. En 1982 a Xunta de Galicia asume como normativa oficial as Normas Ortográficas e Morfolóxicas do Galego, elaboradas por unha comisión que recolle gran parte das propostas da Real Academia Galega e o Instituto da Lingua Galega. Sería demasiado prolixo nomear tódalas obras que antes ou despois se publicaron en relación coa normativización da lingua, pero cabe destacar a Gramática Galega (1986) do Instituto da Lingua Galega, e o Diccionario da Lingua Galega (1990) do ILG e RAG. É preciso sinalar que o diccionario "oficial" tivo unha difusión escasísima. $O$ que realmente se acabou convertendo no diccionario de referencia para o sector oficialista foi o publicado pola editorial Xerais. Para moitos, esta normativa era unha traición á lingua galega por facer, na súa opinión, demasiadas concesións de tipo ortográfico, morfolóxico, sintáctico e léxico ós elementos 
castelanizantes presentes na lingua galega. Non é alleo a esta postura que o goberno daquel entón fose de signo conservador e os defensores do reintegracionismo pertenzan na súa maioría á correntes políticas de esquerda nacionalista, cando non ó independentismo. É o momento da radicalización dun cisma no proceso de normativización entre isolacionistas-oficialistas (que defenden a maior ou menor autosuficiencia do galego fronte o castelán e o portugués) e os lusistas e/ou reintegracionistas (que defenden unha aproximación ó portugués, para compensar a separación de ámbalas dúas linguas por motivos políticos que, segundo eles, nunca tivo que suceder). Representando a esta última corrente atopamos a Associaçom Galega da Língua (AGAL) que publica en 1983 e anos sucesivos o Estudo crítico das Normas Ortográficas e Morfolóxicas do Idioma Galego, Acordo da Ortografia simplificada (a través dunha Commissao para a integraçao da língua da Galiza). A medio camiño entre ámbalas dúas posturas está a Asociación Socio-Pedagóxica Galega, que elabora en 1980 as Orientacións para a escrita do noso idioma, que pretenden ser unha ponte entre normativa oficial e lusista.

A normativa oficial do ano 82, reformada nalgún aspecto no ano 95 , presentaba, por dicilo dun xeito gráfico, unha victoria dos chamados isolacionistas fronte ós lusistas. Nesta normativa, que, por razóns obvias, non podemos recoller aquí completamente, consagrábanse os seguintes aspectos nos puntos máis conflictivos arriba sinalados:

- acentuación: salvo algunhas excepcións e aqueles casos sen correspondencia como as contraccións, aproximábanse moito ás normas de acentuación do castelán.

- uso de apóstrofos para marcar elisión: non se recolle na escrita.

- uso de guións: Fíxanse as normas para os alófonos do artigo (con e sen guión) tras algunhas formas verbais (rematadas en -s, -r e diptongo), algúns determinantes, adverbios e certas preposicións: vou merca-lo libro, buscache-lo rapaz, pola mañá, tódolos días, u-lo neno ...

- representación gráfica da apertura das vocais en caso de homografías: o til marca a apertura (óso/oso)

- representación de fonemas como $/ \mathrm{f} /$ ou $/ \mathrm{n} /$ : o grafema $x$ para representa-lo son $/ \mathrm{S} /$ en tódolos contextos e o $\tilde{n}$ para o $/ \mathrm{n} /$, fronte a outras opcións como o $n h$ do portugués ou o ny do catalán.

- emprego do v/b e do h: tratase de seguir un criterio etimolóxico non coincidente sempre coas solucións do castelán: avogado.

- representación ou non do fenómeno da gheada e o seseo: non se recolle.

- Polimorfismo: Trátase de evitar, aínda que persiste en algunhas formas como nos demostrativos neutros: esto/isto.

- Contraccións: Aconsellábase, pero admitíanse as dúas opcións, pola solución ó para a contracción de preposición $a$ co artigo.

A reforma aprobada en xullo deste ano pola RAG e o ILG non é tan radical como os reintegracionistas puidesen desexar pero supón, na miña opinión, unha concesión a algunhas das súas propostas, esp. no campo do léxico e de moitas terminacións (-bel a carón de -ble: posibel/posible; -aría/-ería ...). Neste punto é preciso aludir á bifurcación que se produciu dentro da tendencia lusista, entre reintegracionismo de "máximos" e 
reintegracionismo de "mínimos", que reflicte a maior ou menor proximidade á lingua portuguesa. Isto, na práctica, levou a tres opcións pero, curiosamente, a maior proximidade dábase entre o reintegracionismo de mínimos e o isolacionismo, e non entre as dúas ramas do reintegracionismo. Ó mesmo tempo, as dúas opcións próximas (mínimos e oficial) son as seguidas pola inmensa maioría dos usuarios, tendo o reintegracionismo de máximos unha presencia residual. Neste contexto é onde se produce o acordo.

Nos apartados arriba sinalados como puntos de conflicto ó longo da historia da normativización habería que sinalar (neste punto basámonos no resume que se recolle na páxina web):

- acentuación: apenas cambios. Non se marca o hiato cando existe $h$ entre as vocais (prohibo).

- uso de apóstrofos para marcar elisión: Admítense para reflecti-la lingua falada.

- uso de guións: Recoméndase o non emprego dos alófonos do artigo con guión, así no lugar de vou merca-lo libro, parece preferirse a forma: vou mercar o libro, aínda que na lingua falada se emprega a forma alófona.

- Polimorfismo: Elimínanse as formas neutras con $e$ : esto.

- Contraccións: Introdúcese a solución dos aoístas como a preferible a carón da solución oísta para a contracción da preposición $a$ co artigo, se ben na lingua falada a práctica maioría pronuncia $/ \mathrm{o} /$.

Neste punto é preciso comentar o que entendo como unha reforma contradictoria, xa que, mentres algunhas solucións como a eliminación dos grupos cultos $c t$ e $c c$ na maioría dos casos (conflito) ou a aceptación de formas como anque e máis formas rematadas en $-z a \mathrm{e}-z o$ (diferenza) supoñen un acercamento ás teses foneticistas, outras reformas como o retorno á solución ao ou a preferencia do non emprego do alófono do artigo na escrita, son un claro afastamento da fala e desa postura máis foneticista dos primeiros casos comentados.

Neste artigo intentei mostrar a grandes rasgos o que foi e é o proceso de normativización da lingua galega, marcado polos dous colosos linguísticos que a rodean ou mesmo a cobren e a situación sociopolítica actual e ó longo da súa historia. Reflectíndose nas diferentes solucións dadas durante este tempo obsérvase a presencia de dúas correntes, a isolacionista-oficialista e a reintegracionista-lusista. A última reforma non é, en parte, outra cousa máis que o resultado desta escisión e o desexo de superala dun xeito aceptable para ámbalas dúas partes. Eu opino que reformas deste tipo nunha lingua con tantos problemas no campo da normalización de uso non traen senón confusión e non axudan no seu proceso cara ó que podemos considerar o estado natural dunha lingua, que é o do seu emprego en tódolos campos de uso cunha norma coñecida e recoñecida como tal por tódolos falantes. Por outro lado, a necesidade de crear unha norma escrita ten a avantaxe de permitirnos elaborala o máis próxima posible a lingua falada. Algunas das propostas aprobadas son un paso atrás nesta dirección, e, ademais, un paso en contradicción con outros e que resultan paradóxicos e contradictorios.

Pero é evidente que a miña pode ser unha postura cómoda e propia de mentes conservadoras pechadas a calquera tipo de cambio, como ocurriu en moitos casos cos críti- 
cos fatalistas que se opuxeron á última reforma ortográfica da lingua alemana e que, pese ás dificultades, está a se abrir paso e a se asentar sen problemas. Esperemos que o mesmo ocurra coa reforma da ortografía galega deste ano.

\section{Bibliografia}

Dosil López, Benxamín / Riveiro Costa, Xesús (1996): Diccionario de Ortografía da Lingua Galega. A Coruña: Fontel.

García de Diego, V. (1984): Elementos de Gramática Histórica Gallega (Fonética-Morfología) 1909. Santiago de Compostela: Verba 23.

Mariño Paz, Ramón (1998): Historia da Lingua Galega. Santiago de Compostela: Sotelo Blanco. Monteagudo, Henrique (Ed.) (1995): Estudios de sociolingüística galega sobre a norma do galego culto. Vigo: Galaxia.

Real Academia Galega / Instituto da Lingua Galega (1995): Normas Ortográficas e Morfolóxicas do Idioma Galego. Vigo.

\section{PROCES NORMIRANJA GALICIJSKEGA JEZIKA}

Zgodovinski razvoj galicijščine določajo nekateri dejavniki, kot so njena skupna preteklost s portugalščino, zakoreninjeno mnenje, da je dialekt portugalščine ali celo španščine, sociopolitični dejavniki, ki izhajajo iz sedanjega položaja Galicije v španski državi ter pomanjkanje dovolj razširjene in splošno sprejete norme za knjižni jezik. Galicijščina ni poznala knjižnega jezika niti uradne rabe od konca srednjega veka do 19. stoletja, ko je nastopil tako imenovani preporod v galicijski književnosti (Rexurdimento) s pesnico Rosalío de Castro na čelu in njenimi Cantares Galegos z leta 1863. Zastoj v razvoju knjižnega jezika je nastopil v obdobju frankizma. Takrat se je večina galicijskih intelektualcev izselila, Buenos Aires pa je postal novo središče galicijske kulture. Ko nastopi demokracija, se tudi za galicijščino začnejo novi časi, saj s statutom o avtonomiji Galicije postane uradni jezik pokrajine. Avtor v svojem članku opisuje današnji položaj jezika, glavne značilnosti procesa njegovega normiranja in najnovejšo reformo pravopisa. 